Original Article

\title{
INTESTINAL ABSORPTION OF EPROSARTAN MESYLATE FROM SELF EMULSIFYING SYSTEM AND CYCLODEXTRIN COMPLEX
}

\author{
MOHAMMED M. ABDOL QUADER*, MOHAMED A. OSMAN, GAMAL M. EL MAGHRABY \\ Department of Pharmaceutical Technology, College of Pharmacy, University of Tanta, Tanta, Egypt \\ Email: maquader2014@gmail.com
}

Received: 18 Nov 2016 Revised and Accepted: 29 Dec 2016

\section{ABSTRACT}

Objective: The aim of this work was to determine the intestinal membrane transport parameters of eprosartan mesylate (EM) and to investigate self-nano emulsifying drug delivery systems (SNEDDS) and inclusion complexation with hydroxypropyl $\beta$ cyclodextrin (HP $\beta C D$ ) for enhanced intestinal absorption of eprosartan mesylate.

Methods: The intestinal absorption was monitored using the in situ rabbit intestinal perfusion technique. SNEDDS was developed using labrafil, Lauroglycol with a tween in the presence of ethanol. Inclusion complexation was achieved by construction of phase solubility diagram in the presence of HP $\beta C D$. The prepared complex was evaluated using Fourier Transform Infrared Spectroscopy (FTIR) and differential scanning calorimetry (DSC).

Results: The drug was found to be poorly absorbed from the jejuno-ileum and the colon with the absorption being mainly through paracellular pathway. An inclusion complex was developed between the drug and HP $\beta C D$. Perfusion of the drug in the nanoemulsion formulation or as an inclusion complex resulted in a significant increase in the intestinal absorption of the drug compared with the control.

Conclusion: SNEDDS and inclusion complexation are promising strategies for enhanced intestinal absorption of eprosartan mesylate.

Keywords: Eprosartan, Self-nano emulsifying, Inclusion complexation, Hydroxypropyl $\beta$ cyclodextrin, Labrafil, Lauroglycol, Tween

(C) 2016 The Authors. Published by Innovare Academic Sciences Pvt Ltd. This is an open access article under the CC BY license (http://creativecommons.org/licenses/by/4. 0/) DOI: http://dx.doi.org/10.22159/ijpps.2017v9i2.16215

\section{INTRODUCTION}

Eprosartan mesylate (EM), is chemically described as the monomethane sulfonate salt of "(E)-2-butyl-1-(p-carboxybenzyl)- $\alpha-2$ thienylmethylimid-azole-5-acrylic acid" [1]. Its molecular weight equals to $520.62 \mathrm{~g} / \mathrm{mol}$ [2]. Eprosartan mesylate is a highly selective angiotensin receptor blocker (ARB) with a unique molecular structure and physiological effects compared with other members of the group. It is a nonbiphenyl, nontetrazole competitive inhibitor with a high affinity for prejunctional subtype 1 angiotensin receptor (AT1) $[3,4]$. It differs from other angiotensin receptor blockers (ARBs) in achieving its action via competitive inhibitory effect $[4,5]$. Eprosartan is not substrate for cytochrome P450 (CYP450) and is mainly excreted unchanged by biliary or renal routes with no active metabolite being detected after oral or intravenous administration [6]. The drug is characterised by a relatively long elimination halflife which can reach $20 \mathrm{~h}$ but no accumulation was recorded after repeated dosing [6]. Eprosartan is an amphiphilic molecule containing allylic and phenylic carboxylic groups and one imidazole (basic) functional group. The latter will be protonated at $\mathrm{pH}$ values lower than 2 [7]. Increasing the $\mathrm{pH}$ will result in deprotonation of the allylic carboxylic group which has an estimated pKa of 2.9. The estimated pKa of the phenylic carboxylic group is 5.9 requiring higher $\mathrm{pH}$ values for deprotonation. Further increase in $\mathrm{pH}$ will result in deprotonation of the protonated imidazole which has an estimated pKa is 6.8 .

According to the pH-partitioning theory, only unionised species or ionneutral will be absorbed by passive diffusion [7]. Taking this into consideration together with the $\mathrm{pH}$-dependent ionisation pattern of the drug, poor intestinal permeability may be considered as an important reason for reduced bioavailability of eprosartan mesylate. In addition, eprosartan mesylate is poorly water soluble with slow dissolution rate which contributes to its low bioavailability after oral administration [8]. The drug thus exhibits low and variable bioavailability with the recorded absolute oral bioavailability being approximately $13 \%$ [6]. To date, the intestinal membrane transport parameters of this drug have not been identified.
The objective of this study was to characterise intestinal membrane permeability parameters of eprosartan mesylate and to enhance its intestinal absorption. This employed the in situ rabbit intestinal perfusion technique with the absorption enhancement depending on complexation with cyclodextrin as cyclodextrins are known to be used for enhancement of solubility, stability and bioavailability [9]. and self-nano emulsifying formulation which are good candidates for oral drug delivery of hydrophobic drugs [10].

\section{MATERIALS AND METHODS}

\section{Chemicals and reagents}

Eprosartan mesylate (Hetero, India) was kindly donated by Pharmed healthcare pharmaceutical company (Hetero pharmed), El Sadat city, Egypt. Potassium dihydrogen orthophosphate, disodium hydrogen phosphate, sodium chloride and potassium chloride were purchased from Isochem, Vert-le-petit, France. Acetonitrile (HPLC grade) was obtained from Fischer scientific, Pennsylvania, USA. Hydroxypropyl- $\beta$-cyclodextrin (HP- $\beta$-CD) was procured from China Eastar Holding Group, Shanghai, China. Absolute ethanol and polysorbate 80 were products of El-Nasr Pharmaceutical Chemicals Company, Cairo, Egypt. Linoleoyl polyoxyl-6 glycerides "Labrafil M 2125 CS®" and propylene glycol monolaurate "Lauroglycol $90 \AA "$ were kindly donated as free samples from Gattefosse, Lyon, France. Ketamine HCl injections were from Sigmatec Pharmaceutical Industries, $6^{\text {th }}$ of October city, Egypt. Chlorpromazine $\mathrm{HCl}$ was from Misr Company for Pharmaceutical Industries, Cairo, Egypt.

\section{Chromatography}

Perfusate samples were analysed for drug content by high-pressure liquid chromatography (HPLC). The method utilised an Agilent apparatus with a photodiode array detector. The separation was performed on zorbax SB-C8 column, $250 \mathrm{~mm}$ in length with $4.6 \mathrm{~mm}$ internal diameter and $5 \mu \mathrm{m}$ particle size. The mobile phase was $0.2 \% \mathrm{v} / \mathrm{v}$ diluted orthophosphoric acid in highly purified water and 
acetonitrile at a ratio of $68: 32(\mathrm{v} / \mathrm{v})$, respectively. The mobile phase was pumped at a rate of $1 \mathrm{ml} /$ minute and the effluent was monitored at $275 \mathrm{~nm}$.

\section{Phase solubility study}

Phase solubility study is mentioned in details in the literature [11, 12]. The aim of this study was to monitor the kinetics of inclusion complexation of eprosartan mesylate/HP $\beta C D$. Solutions containing increasing concentration of HP $\beta C D$ in water were prepared. Excess amounts of the drug were added to each of these solutions, and the resulting suspensions were maintained under continuous stirring at ambient temperature for $72 \mathrm{~h}$. The suspended drug particles were separated by filtration before determining the solubility of the drug by HPLC. The solubility of the drug was plotted as a function of $\mathrm{HP} \beta C D$ concentration to provide the phase solubility diagram. The latter was used to identify the type of complex and to determine the stoichiometric ratio [13].

\section{Fourier transform infra-red (FTIR) spectroscopy}

This was used to study the interaction between the drug and the cyclodextrin. The same technique is used in the complexation study with another drug [14]. The spectra of eprosartan mesylate, HP $\beta C D$ and their combinations were recorded using FTIR spectro- photometer (Bruker Tensor 27, Germany) which was used in potassium bromide diffuse reflectance mode for collecting the IR spectra of the samples. The system is equipped with a DLaTGS detector. Samples were mixed with potassium bromide (spectroscopic grade) and were compressed into disks using hydraulic pressure before scanning through the range of 4000-400 $\mathrm{cm}^{-1}$. The recorded data were analysed using Opus IR, FTIR spectroscopy software.

\section{Differential scanning calorimetry (DSC)}

Thermo grams of eprosartan mesylate, HP $\beta C D$ and the products developed after co-evaporation or kneading of their equimolar mixtures were recorded using differential scanning calorimeter (DSC 60 , Shimadzu, Japan). The samples were loaded into aluminium pans and crimped. The samples were heated under nitrogen at a heating rate of $10^{\circ} \mathrm{C} / \mathrm{min}$, to cover the temperature range of $25-400^{\circ} \mathrm{C}$.

\section{Determination of the phase behaviour}

Phase behaviour of the oil/water/surfactant system was determined to select the composition of the self-nano emulsifying system. The systems employed combinations of Lauroglycol 90 and labrafil M2125CS in combination with tween 80 as a surfactant both in absence and presence of ethanol as a cosurfactant. These systems were mixed according to the composition presented in table 1 .

Table 1: Absorbance at $600 \mathrm{~nm}(\mathrm{~A})$ of different formulae to determine the phase behaviour

\begin{tabular}{|c|c|c|c|c|c|c|}
\hline Formula & Lb* & Lg** & Tween 80 & T: $\mathrm{E}^{* * *} 2: 1$ & T: E 1:2 & $\mathbf{A}$ \\
\hline F1 & 0.05 & 0.05 & 0.40 & - & - & 0.934 \\
\hline $\mathrm{F} 2$ & 0.1 & 0.05 & 0.35 & - & - & 1.172 \\
\hline F3 & 0.05 & 0.1 & 0.35 & - & - & 1.175 \\
\hline $\mathrm{F} 4$ & 0.15 & 0.05 & 0.30 & - & - & 1.286 \\
\hline F5 & 0.1 & 0.1 & 0.30 & - & - & 1.446 \\
\hline F6 & 0.05 & 0.15 & 0.30 & - & - & 1.418 \\
\hline F7 & 0.15 & 0.10 & 0.25 & - & - & 1.534 \\
\hline F8 & 0.10 & 0.15 & 0.25 & - & - & 1.495 \\
\hline F9 & 0.05 & 0.05 & - & 0.40 & - & 0.897 \\
\hline F10 & 0.05 & 0.10 & - & 0.35 & - & 1.459 \\
\hline F11 & 0.15 & 0.10 & - & 0.25 & - & 1.462 \\
\hline F12 & 0.10 & 0.40 & - & - & - & 0.886 \\
\hline F13 & 0.40 & 0.05 & 0.05 & - & - & 1.476 \\
\hline F14 & 0.05 & 0.40 & 0.05 & - & - & 1.085 \\
\hline F15 & - & 0.40 & 0.10 & - & - & 0.824 \\
\hline F16 & 0.05 & 0.05 & - & 0.40 & - & 0.645 \\
\hline F17 & 0.05 & 0.10 & - & 0.35 & - & 1.7 \\
\hline F18 & 0.15 & 0.15 & - & - & 0.20 & 1.328 \\
\hline F19 & 0.05 & 0.05 & 0.40 & - & 0.80 & 0.096 \\
\hline F20 & 0.05 & 0.05 & 0.40 & - & 0.50 & 0.031 \\
\hline
\end{tabular}

The amount of each material is presented as $\mathrm{g} / 100 \mathrm{ml}$ of the buffer, ${ }^{*} \mathrm{lb}=$ labrafil M2125, ${ }^{* *} \mathrm{lg}=$ lauroglycol $90,{ }^{* *} \mathrm{~T}$ : E= tween 80: ethanol

The mixtures were vortex mixed before dispersing $100 \mathrm{mg}$ of each system in $20 \mathrm{ml}$ of hypotonic phosphate buffered saline. The resulting dispersions were evaluated visually for phase separation. Systems showing no phase separation were further characterised by the degree of turbidity by monitoring the absorbance at $600 \mathrm{~nm}$ using UV-VIS spectrophotometer (Shimadzu, UV-1800, Japan). Systems having an absorbance value below 0.1 were considered nanoemulsions with their undiluted system being classified as a self-nano emulsifying system. Those producing absorbance values above 0.1 were considered as a coarse emulsion with the undiluted systems being classified as self-emulsifying drug delivery systems [15].

\section{Preparation of perfusion solutions}

Solutions of the drug $(30 \mu \mathrm{g} / \mathrm{ml})$ were prepared in a hypotonic phosphate buffered saline with pH adjusted to 7.4 and 6.6 for jejunoileum and ascending colon, respectively. This was used as the control. The system containing tween 80, labrafil, laurogol 90 and ethanol (1.6:0.2:0.2:2 w/w) was diluted (16 in 1000) with the same buffer and was used as a solvent for the drug to prepare test perfusion solution. Another perfusion solution was prepared using HP $\beta C D$ which was added at a 1:1 molar ratio with the drug. This was prepared in the same buffer system with the $\mathrm{pH}$ being adjusted as before.

\section{Isolated intestinal segment preparation}

The study employed the in situ rabbit intestinal perfusion technique. The study protocol was approved by the ethical committee of the college of pharmacy, university of Tanta (approval number, 206014). The procedures for the preparation of isolated intestinal segments are well documented in literature with the detailed presentation being reported recently $[15,16]$. The study employed 9 male albino rabbits with an average weight of $2-2.25 \mathrm{~kg}$ obtained from Tanta animal house. The rabbit was anaesthetized by intramuscular (i. m.) injections of ketamine $\mathrm{HCl}$ (2 doses of 45 $\mathrm{mg} / \mathrm{kg}$ at $15 \mathrm{~min}$ intervals and repeated doses of $25 \mathrm{mg} / \mathrm{kg}$ when needed). Chlorpromazine $\mathrm{HCl}$ was used as a muscle relaxant and was given intramuscularly $(2 \mathrm{mg} / \mathrm{kg})$ before anaesthesia.

After induction of anaesthesia, the rabbit was laid down in a supine position on a heating pad to maintain physiologic body temperature. The abdominal area of interest was shaved with depilatory cream before making a midline longitudinal incision of $6-8 \mathrm{~cm}$ long. For jejuno-ileum the proximal end (at least $25 \mathrm{~cm}$ from pylorus) was tied 
off using a surgical thread and cannulated using a 3-way stopcock cannula. The desired length $(30 \mathrm{~cm})$ was measured, and the distal end was cannulated using an L-shaped glass cannula. For the ascending colon, the proximal end was tied off immediately after the ampulla coli and the distal end was tied off. Two small incisions were made, and the colon was cleaned by gentle hand squeezing of the segment. Both ends were then cannulated as before. Complete cleaning of the segment was achieved by infusing a $37{ }^{\circ} \mathrm{C}$ normal saline solution through the proximal end. The rabbit was utilised to study permeability in both segments simultaneously. The remaining parts of the intestine were returned into the abdominal cavity for better temperature control. Segments under study were arranged in a uniform $S$ to multi-S-pattern to keep a regular flow without kinks or obstructions and were kept moistened and warm by covering with a gauze pad moistened regularly with a $37^{\circ} \mathrm{C}$ normal saline solution.

At the end of the experiment, the rabbit was sacrificed, and the intestinal segments under study were excised and accurately measured.

The perfusion solution was perfused into the intestinal segment at a flow rate of $0.27 \mathrm{ml} / \mathrm{min}$ using a constant rate perfusion pump (Harvard-22, Harvard apparatus, USA). The effluent from each segment was collected at 10 min intervals for 120 min in dry glass tubes. The volume of each sample was measured accurately.

\section{Data analysis}

The net water flux was calculated as the difference between the theoretical volume (based on the flow rate) and the actual volume of the perfusate collected. The recorded drug concentration was normalised on the base of the net water flux. The ratio between the normalised concentration in the collected perfusate $\left\{\mathrm{C}_{\text {(out) }}\right\}$ and that at the inflow $\left\{\mathrm{C}_{(\mathrm{in})}\right\}$ was calculated. The average of the calculated ratios for the samples collected from 70 to 120 min was taken as the steady-state ratio, $\left\{\mathrm{C}_{\text {(out) }} / \mathrm{C}_{\text {(in })}\right\}_{\text {ss. }}$ This ratio is the fraction remaining after perfusion and is used to calculate the permeability-area product $(\mathrm{PeA})$ in which $\mathrm{A}$ is the effective surface area $\left(\mathrm{cm}^{2}\right)$ and $\mathrm{Pe}$ is the apparent permeability coefficient $(\mathrm{cm} / \mathrm{min})$ using the following equation.

$$
\left\{\frac{\mathrm{C}(\mathrm{out})}{\mathrm{C}(\mathrm{in})}\right\} \mathrm{ss}=\exp ^{-(\mathrm{PeA} / \mathrm{Q})}
$$

Where, $Q$ is the average flow rate within the intestinal segment $(\mathrm{ml} / \mathrm{min})$.

$$
\mathrm{PeA}=-\mathrm{Q} \cdot \ln \left\{\frac{\mathrm{C}(\mathrm{out})}{\mathrm{C}(\mathrm{in})}\right\} \mathrm{ss}
$$

The fraction remaining after perfusion was used to calculate the fraction absorbed indirectly. This was achieved using equation 3.

$$
\mathrm{Fa}=1-\left\{\frac{\mathrm{C}(\mathrm{out})}{\mathrm{C}(\mathrm{in})}\right\}=1-\exp ^{-(\mathrm{PeA} / \mathrm{Q})}
$$

The extent of intestinal absorption was expressed by calculation of the length of the intestine remaining after complete drug absorption. This parameter is defined as the anatomical reserve length (ARL). This is given by equation 4 .

$$
\mathrm{ARL}=\mathrm{L} *-\mathrm{l} *
$$

Where $L^{*}$ is the maximal intestinal length available for absorption $(\mathrm{cm})$, and $\mathrm{l}^{*}$ is the intestinal length along which absorption is complete $(\mathrm{cm})$. Theoretically due to the logarithmic nature of the equations, the concentration of the drug in the lumen will not deplete completely at the intestinal length $\left(\mathrm{l}^{*}\right)$. Accordingly, a $5 \%$ fraction of drug remaining was taken as an approximate indication for complete absorption. This was used to calculate $l^{*}$ based on equation (5) which is derived from equation (1).

$$
0.05=\exp ^{-(\text {PeA.l*/Q) }}
$$

Where PeA is the effective permeability surface area product normalised to length, and $\mathrm{l}^{*}$ is the length required for $95 \%$ absorption (L95\%) of a given solute.

Intestinal absorption is the sum of the contribution of both diffusive and convective processes. The latter corresponds to the water flux effect. The actual amount of drug absorbed per unit time can be expressed using equation (6).

$$
\mathrm{Js}=\mathrm{Ks}(\mathrm{C}-\mathrm{CP})+\Phi \mathrm{sJwC} .
$$

Where $\left[K_{s}\left(C-C_{p}\right)\right]$ represents the diffusive process, $\left.\left[\Phi_{s}\right]_{w} C\right]$ indicates convective process and Js is the rate of absorption of the drug from the lumen $(\mathrm{mg} / \mathrm{min}) . \mathrm{K}_{\mathrm{s}}$ is the diffusive permeability coefficient, and $C$ and $C_{p}$ are the drug concentrations in the lumen and plasma, respectively. $\Phi_{\mathrm{s}}$ is the sieving coefficient of the drug. $\mathrm{J}_{\mathrm{w}}$ is the water flux which is an absorption-secretion mechanism. Due to sink conditions of the blood which is maintained at steady state, equation (6) is reduced to:

$$
\mathrm{Jss}=\mathrm{KsCss}+\Phi \mathrm{s} \mathrm{JwCss} \ldots \ldots \ldots \ldots \ldots(7)
$$

Where $\mathrm{J}_{\mathrm{ss}}$ is the steady-state solute flux $(\mathrm{mg} / \mathrm{min})$ and $\mathrm{C}_{\mathrm{ss}}$ is a concentration of drug remaining in the lumen at a steady-state concentration $(\mathrm{mg} / \mathrm{ml})$. Rearrangement of equation (7) gives the following equation:

$$
\frac{\mathrm{Jss}}{\mathrm{Css}}=\mathrm{Ks}+\Phi \mathrm{s} \mathrm{Jw} \ldots \ldots \ldots \ldots \ldots \ldots \ldots(8)
$$

The term $\mathrm{J}_{\mathrm{ss}} / \mathrm{C}_{\mathrm{ss}}$ represents the overall absorptive clearance of drug $(\mathrm{ml} / \mathrm{min})$, irrespective to the mechanism of absorption which is determined experimentally as PeA (equation 2). Plotting PeA as a function of the water flux will provide a line the slope of which can be taken as a measure for the sieving coefficient and the intercept with the y-axis will provide a measure for the diffusive part of the absorptive clearance.

\section{RESULTS AND DISCUSSION}

\section{High-pressure liquid chromatography}

The analytical method validation was conducted according to the guidelines of the International Conference of Harmonization [16]. The drug was eluted after a retention time of 5.6 min producing a symmetric peak. The USP tailing factor was 1.0 and number of plates per column was 8927 "on half-width method basis". The calibration curve of eprosartan mesylate was plotted from the recorded peak areas as a function of drug concentration (fig. 1).

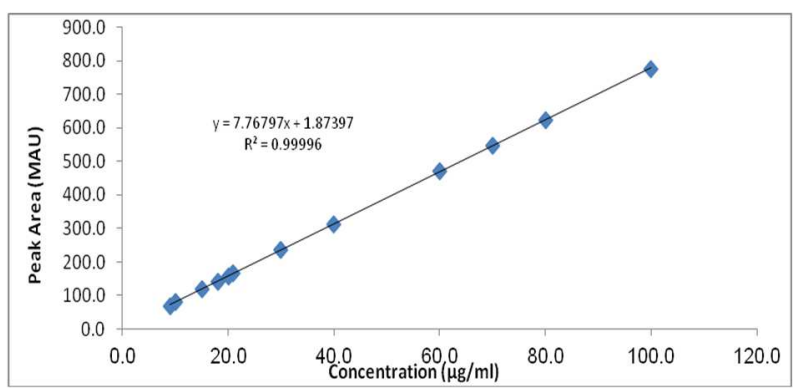

Fig. 1: Calibration curve of eprosartan mesylate after HPLC analysis

The linear regression of the calibration curve of eprosartan mesylate produced an equation of $y=7.768( \pm 0.06) x+1.874( \pm 2.8)$ and a value of $\left(R^{2}\right)$ of 0.99996 . This high correlation reflects the linearity of the calibration curve in the tested range $(9-100 \mu \mathrm{g} / \mathrm{ml})$. The validation parameters are presented in table 2 . The accuracy was assured by determining the \% recovery of nominal concentrations which were in the range of $15 \mu \mathrm{g} / \mathrm{ml}$ and $100 \mu \mathrm{g} / \mathrm{ml}$. The recovered values were in the range of 99.6 and $100.7 \%$ of the labelled amounts reflecting the accuracy of the method. Inter and intra-day variation were studied to determine the precision of the assay. The precision was measured as the Relative Standard Deviation (RSD) expressed as a percentage over the concentration range of eprosartan mesylate targeted during the analysis. The results revealed RSD values in the range of $0.1-1.4 \%$, indicating the precision of the developed analytical method (table 2). 
Table 2: The HPLC validation parameters of eprosartan mesylate

\begin{tabular}{|c|c|c|c|}
\hline & Recovered Conc. $\mu \mathrm{g} / \mathrm{ml}$ & \% RSD & \% recovery \\
\hline Nominal Conc. $(\mu \mathrm{g} / \mathrm{ml})$ & Interday & & \\
\hline 15 & $15.1( \pm 0.01)$ & 0.1 & $100.7( \pm 0.1)$ \\
\hline 30 & $30.0( \pm 0.4)$ & 1.4 & $100.0( \pm 1.3)$ \\
\hline 60 & $60.0( \pm 0.8)$ & 1.3 & $100.1( \pm 1.4)$ \\
\hline 100 & $100.5( \pm 1.3)$ & 1.3 & $100.5( \pm 1.4)$ \\
\hline Nominal Conc. $(\mu \mathrm{g} / \mathrm{ml})$ & Intraday & & \\
\hline 18 & $17.9( \pm 0.1)$ & 0.5 & $99.6( \pm 0.5)$ \\
\hline 21 & $21.0( \pm 0.1)$ & 0.5 & $99.9( \pm 0.5)$ \\
\hline 100 & $99.8( \pm 0.2)$ & 0.1 & $99.8( \pm 0.2)$ \\
\hline
\end{tabular}

The $\%$ recovery is a measure of accuracy, and \%RSD are used as a measure of precision; All concentrations are shown as mean \pm SD ( $=3$ ), The limit of detection and limit of quantitation were calculated to be $0.34 \mu \mathrm{g} / \mathrm{ml}$ and $1.03 \mu \mathrm{g} / \mathrm{ml}$ respectively.

\section{Phase solubility diagram}

The effect of HP $\beta C D$ concentration on the aqueous solubility of eprosartan mesylate was used to construct the phase solubility diagram which was a plot of the molar solubility of the drug as a function of the molar concentration of HP $\beta C D$. This is shown in fig. 2 which reflects a linear relationship with $\mathrm{R}^{2}=0.979$ indicating an $\mathrm{A}_{\mathrm{L}}$ type.

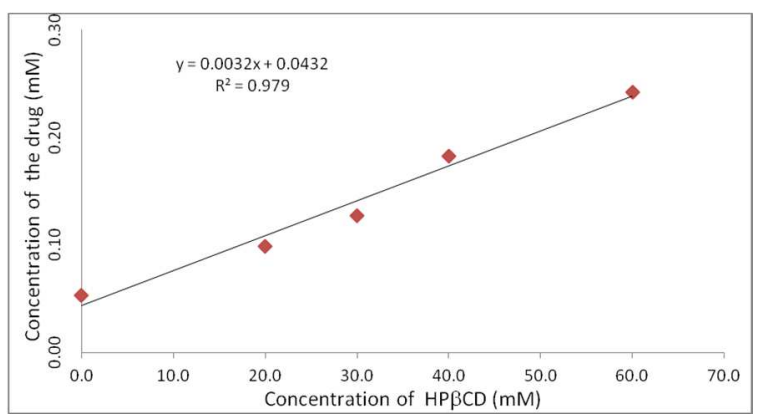

Fig. 2: Phase solubility diagram

This phase solubility diagram suggests a 1:1 molar ratio as the stoichiometric ratio. Complexation efficiency of eprosartan mesylate $/ \mathrm{HP} \beta C D$ complex $(\mathrm{CE})=0.003$ calculated according to the following equation [17].

$$
\mathrm{CE}=\text { So. } \mathrm{K} 1: 1=\frac{\text { Slope }}{(1-\text { Slope })}
$$

\section{FTIR spectroscopy}

FTIR spectra (fig. 3) were recorded to assess the possibility of the inclusion complex formation between eprosartan mesylate and HP $\beta C D$. The FTIR spectrum of unprocessed eprosartan mesylate showed a characteristic band at $3471 \mathrm{~cm}^{-1}$ for $\mathrm{OH}$ stretching, two bands at 3134 $\mathrm{cm}^{-1}$ and $3041 \mathrm{~cm}^{-1}$ for aromatic $=\mathrm{C}-\mathrm{H}$ stretching. The three bands at $2962 \mathrm{~cm}^{-1}, 2934 \mathrm{~cm}^{-1}$ and $2875 \mathrm{~cm}^{-1} \mathrm{can}$ be due to $\mathrm{C}-\mathrm{H}$ stretching vibrations. A strong, sharp band at $1706 \mathrm{~cm}^{-1}$ was recorded representing the first $\mathrm{C}=0$ stretching (conjugated to vinyl double bond). The absorption band of the second $\mathrm{C}=\mathrm{O}$ (conjugated to an aromatic ring) was recorded as a weak peak at $1697 \mathrm{~cm}^{-1}$, nearly fusing with that of the first $\mathrm{C}=0$ [8]. Two bands were recorded at $1643 \mathrm{~cm}^{-1}$ and $1615 \mathrm{~cm}^{-1}$ representing the conjugated aliphatic $\mathrm{C}=\mathrm{C}$. The characteristic absorption bands of $\mathrm{SO}_{2}$ (of the mesylate group) were detected at $1238 \mathrm{~cm}^{-1}$ for asymmetric stretching vibration with the symmetric stretching being recorded as two bands at $1161 \mathrm{~cm}^{-1}$ and $1042 \mathrm{~cm}^{-1}$. An absorption peak was seen at $770 \mathrm{~cm}^{-1}$ for C-S linkage stretching.

The FTIR spectrum of HP $\beta C D$ showed the characteristic absorption bands of the oligomer. These included the broadband of $\mathrm{O}-\mathrm{H}$ stretching vibration which was seen at $3413 \mathrm{~cm}^{-1}$ with its bending vibrations being noticed at $1639 \mathrm{~cm}^{-1}$. The $\mathrm{C}-\mathrm{H}$ stretching vibrations were shown at 2970 $\mathrm{cm}^{-1}$ and $2930 \mathrm{~cm}^{-1}$ with the asymmetric $\mathrm{C}-\mathrm{H}$ bending vibration appearing at $1457 \mathrm{~cm}^{-1}$ [18]. The C-O stretching vibrations were detected at $1155 \mathrm{~cm}^{-1}$ and $1084 \mathrm{~cm}^{-1}$. A characteristic band at $854 \mathrm{~cm}^{-1}$ for $\alpha-1,4$-glycosidic bond was revealed by the spectrum. Similar spectrum was recorded by other investigators with the absorption bands being similarly assigned [19].

The FTIR spectra of the prospective complex prepared by kneading and co-evaporation produced FTIR spectra in which the absorption bands corresponding to aromatic $=\mathrm{C}-\mathrm{H}$ stretching of the drug were absent. Both spectra showed an obvious broadening of the characteristic $\mathrm{O}-\mathrm{H}$ band compared with that recorded in the case of unprocessed eprosartan mesylate reflecting the probability of intermolecular H-bonding with HP $\beta C D$. In addition, the absorption band corresponding to the $\mathrm{C}$-S bond of the drug was not clearly defined in the spectra of the prospective complex. These findings highlight the complexation process. It is interesting to emphasise that the peak corresponding to the second carbonyl group of the drug becomes clearer compared with that recorded in the spectrum of the unprocessed drug. This reflects possible immobilisation of the group and provides additional evidence for complex formation (fig. 3).

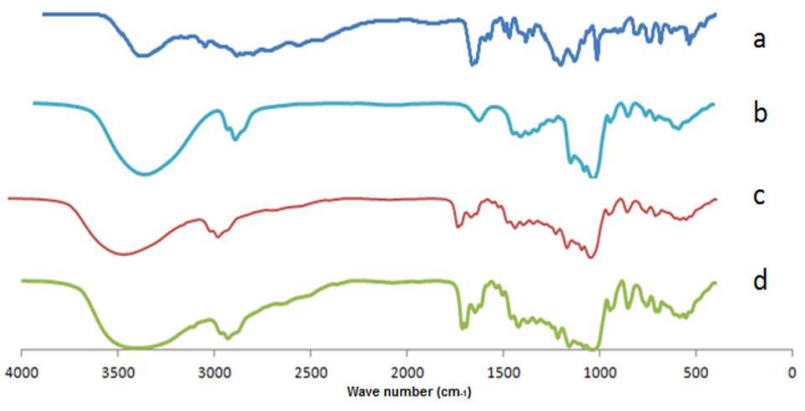

Fig. 3: FTIR spectra of (a) eprosartan mesylate; (b) HP $\beta C D$; (c) HP $\beta C D$ : drug mixture prepared by co-evaporation technique; (d) HP $\beta C D$ : drug mixture prepared by kneading technique

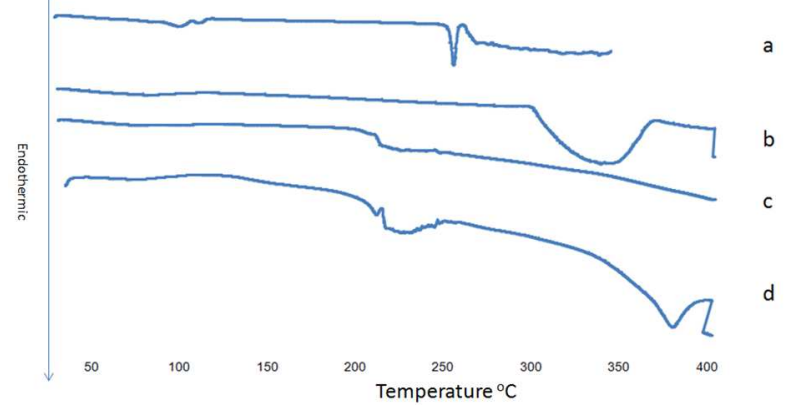

Fig. 4: DSC thermograms of (a) eprosartan mesylate; (b) HP $\beta C D$; (c) HP $\beta C D$ : drug mixture prepared by co-evaporation technique; (d) HP $\beta C D$ : drug mixture prepared by kneading technique 


\section{DSC}

The DSC traces of the unprocessed drug, HP $\beta C D$ and their prospective complex are shown in fig. 4. The thermogram of eprosartan mesylate showed two endothermic peaks in the range of $87^{\circ} \mathrm{C}$ to $114{ }^{\circ} \mathrm{C}$. These can be attributed to the liberation of the adsorbed water and/or the water of crystallisation. Dehydration behaviour of eprosartan mesylate dihydrate was reported in the literature showing gradual evaporation of the water of crystallisation upon heating [20].

The thermogram also revealed a sharp endothermic peak starting at $243^{\circ} \mathrm{C}$ and ending at $258^{\circ} \mathrm{C}$ with transition midpoint Tm at $253^{\circ} \mathrm{C}$. This endothermic peak corresponds to the melting point of the drug and correlates well with suppliers` specifications and the published data on the same drug [8].

The thermogram of HP $\beta C D$ showed a broad endothermic peak starting at $32.47^{\circ} \mathrm{C}$ and ending at $113.94{ }^{\circ} \mathrm{C}$ with a transition midpoint at 80.56 ${ }^{\circ} \mathrm{C}$ which can be attributed to the liberation of adsorbed moisture. The thermogram also showed another endothermic peak with a Tm at 340 ${ }^{\circ} \mathrm{C}$ due to complete melting with the decomposition of the oligomer (fig. 4.0). Similar thermal behaviour has been published for the same compound with a complete decomposition being noticed between 300 ${ }^{\circ} \mathrm{C}$ and $400{ }^{\circ} \mathrm{C}[19]$.
The thermograms of the drug/HP $\beta C D$ complex were characterised by the absence of the main endothermic peak of the drug reflecting its presence in the form of molecular dispersion state. This strengthens the findings of the FTIR study and confirms the formation of the inclusion complex between the drug and the oligomer. Similar thermal changes were recorded after complexation of genistein with cyclodextrin with the findings being considered supportive for inclusion complexation [21]. A similar pattern was recorded for complexes prepared by co-evaporation and kneading (fig. 4).

\section{Membrane transport parameters}

The intestinal absorption of the drug was monitored using the in situ rabbit intestinal perfusion technique. This technique is being in use for a long period of time with many articles being published recently utilising the same method due to its advantages. The rabbit was selected as the test animal due to its intestinal physiology which simulates the human system [15]. Perfusion of an aqueous solution of eprosartan mesylate (control) through the selected intestinal segments produced membrane transport parameters highlighting the incomplete absorption of the drug from the tested intestinal segments (table 3).

Table 3: Membrane transport parameters of eprosartan mesylate after perfusion through rabbit intestinal segments (dilution with corresponding buffers was performed for each)

\begin{tabular}{lllllll}
\hline Parameter & Control & & SNEDDS $^{* *}$ & & HP $\beta C^{* * *}$ \\
\cline { 2 - 7 } & Jejuno-ileum & Ascending colon & Jejuno-ileum & Ascending colon & Jejuno-ileum & Ascending colon \\
\hline $\mathrm{PeA} / \mathrm{l}(\mathrm{ml} / \mathrm{min}$. & 0.00115 & 0.00885 & 0.00164 & 0.00757 & 0.00161 & 0.00647 \\
$\mathrm{~cm})$ & $( \pm 0.0001)$ & $( \pm 0.00449)$ & $( \pm 0.0002)$ & $( \pm 0.00081)$ & $( \pm 0.0001)$ & $( \pm 0.0014)$ \\
$\mathrm{R}_{\text {out }} / \mathrm{R}_{\text {in }}$ & $0.85927( \pm 0.0164)$ & $0.75473( \pm 0.08496)$ & $0.79135( \pm 0.0272)$ & $0.73089( \pm 0.02624)$ & $0.79870( \pm 0.0166)$ & $0.84064( \pm 0.0180)$ \\
$\% \mathrm{Fa}$ & $14.1( \pm 1.64)$ & $24.5( \pm 8.5)$ & $20.9( \pm 2.7)$ & $26.9( \pm 2.6)$ & $20.1( \pm 1.7)$ & $15.9( \pm 1.8)$ \\
$\mathrm{L} 95 \%(\mathrm{~cm})$ & $780.7( \pm 97.66)$ & $235.2( \pm 125.9)$ & $578.3( \pm 163.6)$ & $116.8( \pm 13.4)$ & $647.0( \pm 169.7)$ & $142.9( \pm 44.1)$ \\
$\mathrm{ARL}(\mathrm{cm})$ & $-600.7( \pm 97.66)$ & $-220.2( \pm 125.9)$ & $-398.3( \pm 163.6)$ & $-101.8( \pm 13.4)$ & $-467.0( \pm 169.7)$ & $-127.9( \pm 44.1)$ \\
$\mathrm{JW}(\mathrm{ml} / \mathrm{min})$ & $0.11677( \pm 0.0187)$ & $0.09997( \pm 0.02026)$ & $0.12913( \pm 0.006)$ & $0.0936( \pm 0.00544)$ & $0.1300( \pm 0.0089)$ & $0.06573( \pm 0.0028)$ \\
$\mathrm{JW} / \mathrm{l}(\mathrm{ml} / \mathrm{min}$. & 0.00409 & $0.01301( \pm 0.0042)$ & 0.00429 & 0.01010 & 0.00455 & 0.01012 \\
$\mathrm{~cm})$ & $( \pm 0.0003)$ & & $( \pm 0.0002)$ & $( \pm 0.00117)$ & $( \pm 0.0006)$ & $( \pm 0.0016)$ \\
\hline
\end{tabular}

All results are shown as mean \pm SEM (n=3), *The control was the drug solution $(30 \mu \mathrm{g} / \mathrm{ml}) .{ }^{* *}$ SNEDDS $(30 \mu \mathrm{g} / \mathrm{ml}) .,{ }^{* * *}$ The drug: HP $\beta C D 1: 1$ inclusion complex $(30 \mu \mathrm{g} / \mathrm{ml})$.

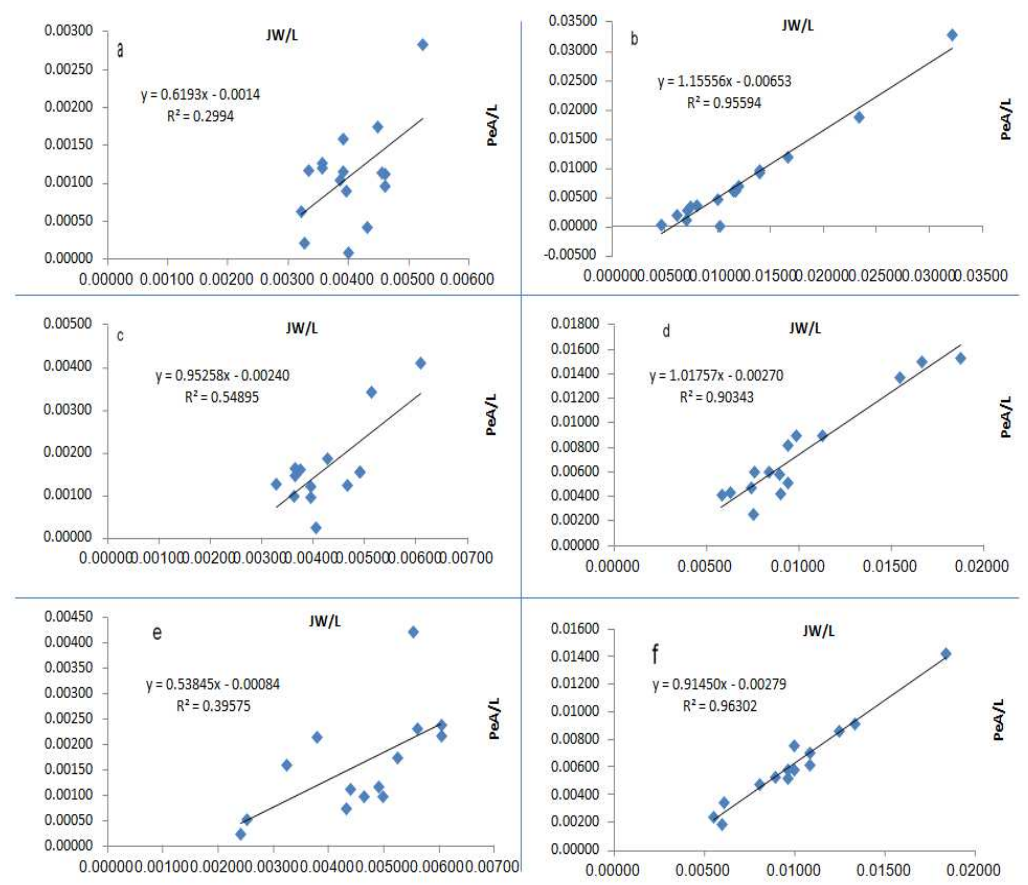

Fig. 5: Absorptive clearance of eprosartan mesylate versus water flux. (a) control rabbits jejunoileuum segment; (b) control rabbits Colon segment; (c) SNEDDS rabbits jejunoileuum segment; (d) SNEDDS rabbits Colon segment; (e) HP $\beta C D$ rabbits jejunoileuum segment; (f) HP $\beta C D$ rabbits Colon segment Parameters are normalized to segment length 
This incomplete absorption was manifested as low absorptive clearance with PeA/l being 0.00115 and $0.00885 \mathrm{ml} / \mathrm{min}$. $\mathrm{cm}$ for the jejunoileum and colon, respectively. The fraction absorbed was 14.1 and $24.5 \%$ for the segments, respectively. The anatomical reserve length (ARL) was negative in both segments (table 3 ). These data confirm the poor absorption characteristic of the drug. This can be attributed to its existence in an ionised form in the $\mathrm{pH}$ of the tested intestinal segments. Dependence of drug absorption on the degree of ionisation was noticed by the same technique [15]. Comparing the intestinal membrane transport parameters recorded after perfusion through the jejunoileum with those recorded in case of the colon, the absorption pattern can be considered site dependent with the colon being superior per unit length.

To investigate the pathway of drug absorption, the absorptive clearance of the drug from each segment was correlated to with corresponding water flux according to Lifson's model [16]. This was achieved by plotting the absorptive clearance as a function of the water flux (fig. 5). The linear regression analysis of such plots produced a slope equal to 0.62 with negative intercept. This slope was significantly different from zero in the jejunoileum segment and so, indicating the dependence of absorptive clearance of eprosartan mesylate on water flux. The same pattern was seen in the colon (fig. 5). This finding with the negative intercept indicates that the absorption is mainly convective which may explain the superiority of colonic absorption compared with the jejunoileum [22]. Calculated water flux values correlate with the suggested absorption pathway with the water flux per unit length being higher from the colon (table 3).

Perfusion of eprosartan mesylate in the form of nanoemulsion resulted in a significant increase in the intestinal absorption of the drug compared with the control. This was manifested as a trend of increased percentage fraction absorption from with a reduction in the $\mathrm{L} 95 \%$. The same trend was noticed in the jejuno-ileum and the colon (table 3). The same trend was shown after perfusion of the drug in the form of an inclusion complex with HP $\beta C D$. The use of nanoemulsion was able to extend the absorption window of furosemide which is known to be mainly ionised in the intestinal $\mathrm{pH}$ [15]. This agrees with the current finding which showed good potential for enhancing the intestinal absorption of eprosartan mesylate which is known to be mainly ionised at intestinal $\mathrm{pH}$.

\section{CONCLUSION}

SNEDDS was successfully developed using labrafil, lauroglycol with Tween 80 in the presence of ethanol. Eprosartan mesylate formed an equimolar inclusion complex with HP $\beta C D$. Eprosartan mesylate is incompletely absorbed from the intestine. Self-nano emulsifying formulation and inclusion complexation were promising for enhanced intestinal absorption of eprosartan mesylate, and these techniques were thought to provide good tools for researchers in the field to expand its use in enhancing absorption of similar drugs.

\section{ACKNOWLEDGEMENT}

I would like to express my gratitude to Pharmed Healthcare pharmaceutical company (Hetero pharmed, Egypt) for supporting by analytical instruments and special appreciation for Mr. Ahmed M. Elewa, M. Sc and Ibrahim A. El belkasy, B. Sc. from methodology dept. for guidance during HPLC analysis of eprosartan mesylate.

\section{CONFLICTS OF INTERESTS}

\section{Declared none}

\section{REFERENCES}

1. Dalvi VJ PDD, Tambe AP, Khanvilkar VV, Kadam VJ. Analytical methods for estimation of eprosartan mesylate: a review. Pharma Sci Monit 2013;4:371-87.

2. Chandana O, Kumar DS, Babu RR. Method development and validation of eprosartan mesylate and its impurities using reverse phase high-performance liquid chromatography. Int J Curr Pharm Res 2016;8:49-53.

3. Brooks DP, Ohlstein EH, Ruffolo RR. Pharmacology of eprosartan, an angiotensin ii receptor antagonist: exploring hypotheses from clinical data. Am Heart J 1999;138:S246-S51.

4. Ram CVS, Rudmann MA. Unique dual mechanism of action of eprosartan: effects on systolic blood pressure, pulse pressure, the risk of stroke and cognitive decline. Expert Rev Cardiovasc Ther 2007;5:1003-11.

5. Sica DA, Hollenberg NK. The renal profile of eprosartan. Pharmacotherapy 1999;19:86S-94S.

6. Michel MC, Foster C, Brunner HR, Liu L. A systematic comparison of the properties of clinically used angiotensin ii type 1 receptor antagonists. Pharmacol Rev 2013;65:809-48.

7. Gudipati MR, Jushchyshyn JM, Palepu NR, Venkatesh GM. Eprosartan arginyl charge-neutralization-complex and a process for its preparation and formulation. US Patent; 2003.

8. Bhandaru JS, Malothu N, Akkinepally RR. Characterization and solubility studies of pharmaceutical cocrystals of eprosartan mesylate. Cryst Growth Des 2015;15:1173-9.

9. Sarangi MK, Padhi S. Colon targeted drug delivery system an approach for treating colonic ailments. J Critical Rev 2015;2:12-8.

10. Jyothi BJ, Sreelakshmi K. Design and evaluation of self-nano emulsifying drug delivery system of flutamide. J Young Pharm 2011;3:4-8

11. Ajmera A, Deshpande S, Kharadi S, Rathod K, Patel K, Patel P. Dissolution rate enhancement of atorvastatin, fenofibrate and ezetimibe by inclusion complex with $\beta$-cyclodextrin. Asian J Pharm Clin Res 2012;5:73-6.

12. Mendhe A, Kharwade R, Mahajan U. Dissolution enhancement of poorly water-soluble drug by cyclodextrins inclusion complexation. Int J Appl Pharm 2016;8:60-5.

13. Loftsson T, Masson M, Brewster ME. Self-association of cyclodextrins and cyclodextrin complexes. J Pharm Sci 2004;93:1091-9.

14. Rao M, Sunitha K, Harika K. Influence of hydroxypropyl- $\beta$ cyclodextrin on repaglinide release from sustained release bioadhesive buccal tablets. Asian J Pharm Clin Res 2013;6:184-90.

15. Sultan AA, El-Gizawy SA, Osman MA, El Maghraby GM. Colloidal carriers for extended absorption window of furosemide. J Pharm Pharmacol 2016; 68:324-32.

16. International conference on harmonisation, Q2 (R1) Validation of analytical procedures: Text and methodology; 2005.

17. Loftsson T, Hreinsdóttir D, Másson M. The complexation efficiency. J Inclusion Phenom Macrocyclic Chem 2007;57:545-52.

18. Wang SH, Griffiths PR. Resolution enhancement of diffuse reflectance IR spectra of coals by fourier self-deconvolution: 1 . Ch stretching and bending modes. Fuel 1985;64:229-36.

19. Yuan C, Liu B, Liu H. Characterization of hydroxypropyl- $\beta$ cyclodextrins with different substitution patterns via ftir, gcms, and tg-dta. Carbohydr Polym 2015;118:36-40.

20. Sheng J, Venkatesh GM, Duddu SP, Grant DJ. Dehydration behavior of eprosartan mesylate dihydrate. J Pharm Sci 1999;88:1021-9.

21. Danciu C, Soica C, Csanyi E, Ambrus R, Feflea S, Peev C, et al. Changes in the anti-inflammatory activity of soy isoflavonoid genistein versus genistein incorporated in two types of cyclodextrin derivatives. Chem Cent J 2012;6:1-11.

22. Riad LE, Sawchuk RJ. Absorptive clearance of carbamazepine and selected metabolites in rabbit intestine. Pharm Res 1991;8:1050-5.

\section{How to cite this article}

- Mohammed M Abdol Quader, Mohamed A Osman, Gamal M El maghraby. Intestinal absorption of eprosartan mesylate from the self-emulsifying system and cyclodextrin complex. Int J Pharm Pharm Sci 2017;9(2):302-307. 